\title{
Низкотемпературные омические контакты на основе Ta/Al к гетероэпитаксиальным структурам AIGaN/GaN на кремниевых подложках
}

\author{
(C) Е.В. Ерофеевв ${ }^{1}$, И.В. Федин ${ }^{1}$, В.В. Федина ${ }^{1}$, А.П. Фазлеев ${ }^{2}$ \\ ${ }^{1}$ Научно-исследовательский институт систем электрической связи \\ Томского государственного университета систем управления и радиоэлектроники, \\ 634034 Томск, Россия \\ ${ }^{2} \mathrm{AO} \ll$ Каучно-производственная фрирма „Микран“», \\ 634045 Томск, Россия \\ E-mail: erofeev@sibmail.com
}

(Получена 16 апреля 2018 г. Принята к печати 23 апреля 2018 г.)

Исследованы закономерности формирования низкотемпературного омического контакта на основе Ta/Al к гетероэпитаксиальным структурам $\mathrm{Al}_{0.25} \mathrm{Ga}_{0.75} \mathrm{~N} / \mathrm{GaN}$ на кремниевых подложках. Получены омические контакты на основе композиции $\mathrm{Ta} / \mathrm{Al} / \mathrm{Ti}$ (10/300/20 нм), характеризующиеся низким значением приведенного контактного сопротивления $(0.4 \mathrm{OM} \cdot \mathrm{MM})$, а также гладкой морфологией поверхности контактной площадки и ее края после термической обработки при $T=550^{\circ} \mathrm{C}$ в течение $t=60 \mathrm{c}$ в среде азота.

DOI: $10.21883 /$ FTP.2019.02.47108.8870

\section{1. Введение}

Мощные транзисторы с высокой подвижностью электронов на основе нитрида галлия $(\mathrm{GaN})$ представляют большой интерес с точки зрения полупроводниковой СВЧ электроники [1]. Благодаря уникальным свойствам $\mathrm{GaN}$, транзисторы на его основе имеют большие напряжения пробоя и плотности токов, что позволяет достичь плотность мощности, в 10 раз превышающую таковую у кремниевых и арсенид-галлиевых аналогов [2]. Однако для достижения высоких рабочих характеристик требуются низкорезистивные омические контакты к областям стока и истока GaN-транзистора. Кроме того, необходимо, чтобы омические контакты имели гладкую морфологию поверхности и ровный край, обеспечивающие возможность формирования субмикронных Т-образных затворов $\mathrm{GaN}$-транзисторов методами электронно-лучевой литографии. Таким образом, исследования, направленные на изучение закономерностей формирования омических контактов к $\mathrm{AlGaN} / \mathrm{GaN}$-гетероструктурам, являются актуальными и практически значимыми.

В настоящее время наиболее распространенным омическим контактом к гетероэпитаксиальным структурам $\mathrm{AlGaN} / \mathrm{GaN}$ является многослойная металлизация на основе $\mathrm{Ti} / \mathrm{Al} / \mathrm{Ni} / \mathrm{Au}[3-5]$. Нижний слой Ti, непосредственно контактирующий с полупроводником с образованием соединений TiN в процессе термической обработки, играет значительную роль в формировании низкорезистивного омического контакта. Слой $\mathrm{Al}$ в свою очередь, реагируя с Ті в процессе отжига, способствует формированию фаз $\mathrm{Al}_{3} \mathrm{Ti}$, предотвращая окисление Ti [6,7]. Слой Ni выступает в качестве диффузионного барьера, препятствующего взаимодействию слоя $\mathrm{Al}$ с вышележащим слоем $\mathrm{Au}$, выполняющим защитную функцию. При этом вместо Ni могут быть использованы тугоплавкие металлы, такие как Мо, Та или $\mathrm{Pt}$ [8]. К преимуществам омических контактов на основе $\mathrm{Ti} / \mathrm{Al} / \mathrm{Ni} / \mathrm{Au}$ можно отнести низкое значение приведенного контактного сопротивления $(<0.5$ Ом · мм), а к недостаткам - высокую температуру термообработки $\left(>800^{\circ} \mathrm{C}\right)$, а также развитый рельеф поверхности контактной площадки и неровность ее края.

Альтернативой контактам на основе $\mathrm{Ti} / \mathrm{Al} / \mathrm{Ni} / \mathrm{Au}$ могут быть низкотемпературные омические контакты на основе TiN/Al, Hf/Al или Ta/Al, которые способы формировать низкорезистивный омический контакт к гетероэпитаксиальным структурам $\mathrm{AlGaN} / \mathrm{GaN}$ при низких температурах термической обработки $\left(<600^{\circ} \mathrm{C}\right)$, меньшей температуры плавления слоя алюминия, что позволяет обеспечить гладкую морфологию поверхности контактной площадки, а также ее края.

В работе [9] исследованы электрические характеристики омического контакта на основе композиции TiN/Ti/Al/Ti/TiN (10/20/100/20/50 нм) к гетероэпитаксиальным структурам на основе $\mathrm{Al}_{0.25} \mathrm{Ga}_{0.75} \mathrm{~N} / \mathrm{GaN}$ на кремниевых подложках. Минимальное значение приведенного контактного сопротивления составило 0.67 Ом - мм после термической обработки при температуре $T=550^{\circ} \mathrm{C}$ в течение $t=90 \mathrm{c}$. К преимуществам данного контакта можно отнести совместимость с типовыми кремниевыми технологическими процессами, что позволяет производить мощные GaN-приборы на дешевых $\mathrm{GaN} / \mathrm{Si}$-пластинах большого диаметра по малозатратной кремниевой технологии.

В работе [10] представлены результаты исследования электрических характеристик омического контакта на основе композиции Hf/Al/Ta (15/200/20 нм) к гетероэпитаксиальным структурам на основе $\operatorname{In}_{0.18} \mathrm{Al}_{0.82} \mathrm{~N} / \mathrm{GaN}$ на кремниевых подложках. Минимальное значение приведенного контактного сопротивления составило 0.59 Ом $\cdot$ мм после термической обработки при температуре $T=600^{\circ} \mathrm{C}$ в течение $t=60 \mathrm{c}$.

Однако, несмотря на низкие температуры термообработки $\left(550-600^{\circ} \mathrm{C}\right)$ и гладкую морфологию поверх- 
ности контактной площадки, омические контакты на основе TiN/Al и Hf/Al по величине приведенного контактного сопротивления (0.59-0.67 Ом - мм) уступают высокотемпературным аналогам на основе $\mathrm{Ti} / \mathrm{Al} / \mathrm{Ni} / \mathrm{Au}$ $(<0.5 \mathrm{OM} \cdot \mathrm{MM})$. Таким образом, задача по уменьшению контактного сопротивления низкотемпературных омических контактов является актуальной и практически значимой.

Цель настоящей работы заключается в снижении приведенного контактного сопротивления низкотемпературных омических контактов на основе Тa/Al к гетероэпитаксиальным структурам $\mathrm{AlGaN} / \mathrm{GaN}$ на кремниевых подложках.

\section{2. Методики эксперимента}

В экспериментах использовались эпитаксиальные гетероструктуры типа $i$-GaN/AlGaN/GaN, выращенные методом металлоорганической газофазовой эпитаксии на подложках кремния диаметром 100 мм. Гетероструктура включала в себя буферный слой на основе легированного железом $\mathrm{GaN}$ толщиной 2 мкм, канальный слой из нелегированного $\mathrm{GaN}$, барьерный слой $\mathrm{Al}_{0.25} \mathrm{Ga}_{0.75} \mathrm{~N}$ толщиной 12 нм и защитный $i$-GaN слой толщиной 2 нм.

Методом плазмохимического травления на пластинах формировалась межприборная мезаизоляция травлением полупроводника в плазме состава $\mathrm{BCl}_{3} / \mathrm{Cl}_{2} / \mathrm{Ar}$ на глубину 180 нм. Далее на поверхности пластин литографическими методами формировалась двухслойная фоторезистивная маска, в которой вскрывались окна для формирования металлизации омических контактов. Затем на части пластин производилось плазмохимическое травление рецесса (заглубления) в барьерном слое. Методом электронно-лучевого напыления в вакууме производилось напыление металлизации омического контакта на основе тонких пленок Тa/Al/Ti (Mo, Ni). Толщины слоев Та и Al варьировались в диапазоне от 5 до 20 нм и от 50 до $300 \mathrm{Hм} \mathrm{соответственно.} \mathrm{При} \mathrm{этом}$ толщина верхнего слоя на основе Ti, Мо или Ni была фиксированной и составляла 20 нм. После напыления металлизации омических контактов фоторезистивная маска удалялась и проводился быстрый термический отжиг контактов при температуре $T=550^{\circ} \mathrm{C}$ в течение $t=60$ с в атмосфере очищенного азота.

Приведенное контактное сопротивление омического контакта измерялось методом линий передач (МЛП). Морфология поверхности контактных площадок исследовалась методом сканирующей электронной микроскопии (СЭМ).

\section{3. Экспериментальные результаты и их обсуждение}

На рис. 1 представлена экспериментальная зависимость величины приведенного контактного сопротивления омического контакта на основе Тa/Al/Ti (10/X/20 нм)

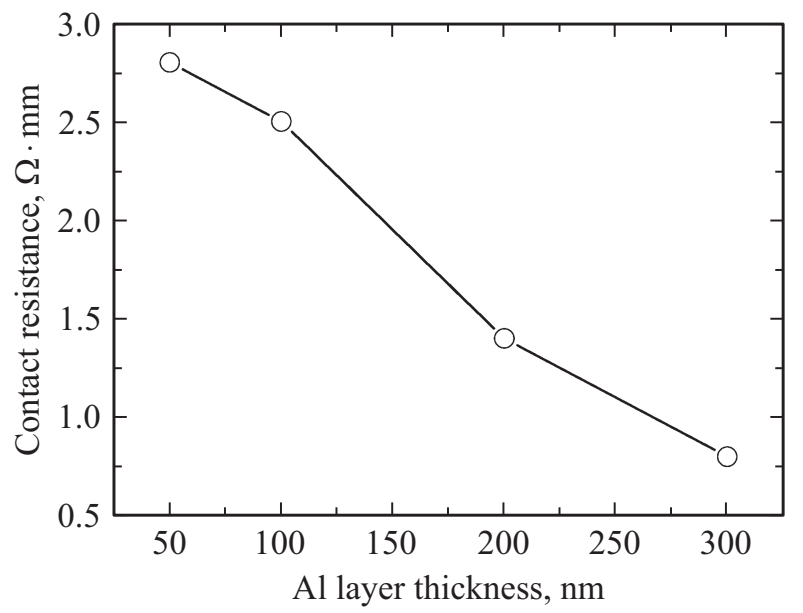

Рис. 1. Экспериментальная зависимость величины приведенного контактного сопротивления омического контакта на основе $\mathrm{Ta} / \mathrm{Al} / \mathrm{Ti}(10 / X / 20 \mathrm{Hм})$ от толщины слоя алюминия в диапазоне от $X=50$ до 300 нм после термической обработки при температуре $T=550^{\circ} \mathrm{C}$ в течение $t=60$ с в среде азота.

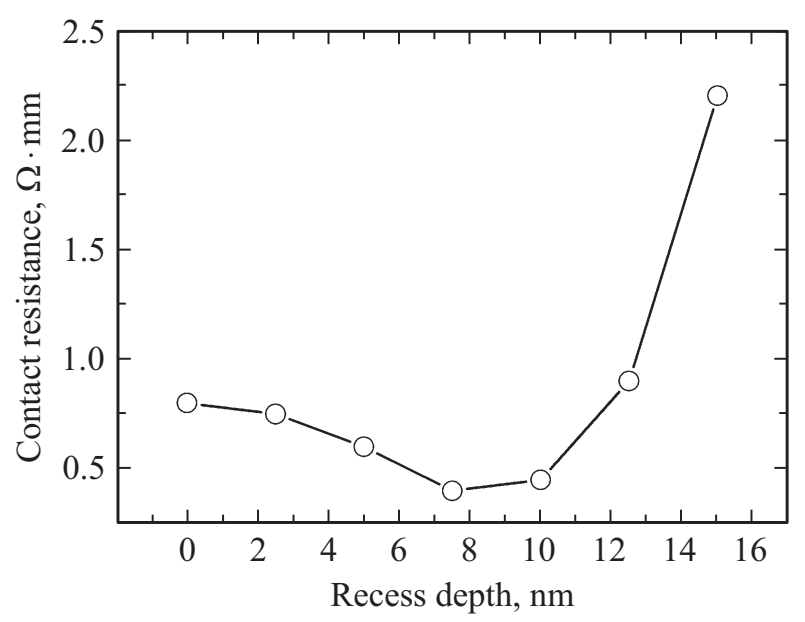

Рис. 2. Экспериментальная зависимость величины приведенного контактного сопротивления омического контакта на основе $\mathrm{Ta} / \mathrm{Al} / \mathrm{Ti}(X / 300 / 20 \mathrm{Hм})$ от толщины слоя тантала в диапазоне от $X=5$ до 20 нм после термической обработки при температуре $T=550^{\circ} \mathrm{C}$ в течение $t=60$ с в среде азота.

от толщины слоя алюминия в диапазоне от $X=50$ до 300 нм после термической обработки при температуре $T=550^{\circ} \mathrm{C}$ в течение $t=60$ с в среде азота.

Видно, что при увеличении толщины слоя Al в диапазоне от 50 до 300 нм наблюдается монотонное уменьшение величины приведенного контактного сопротивления c 2.8 до 0.8 Ом - мм. Полученная закономерность может быть объяснена тем, что по мере нарастания толщины пленки $\mathrm{Al}$ при фиксированной толщине слоя Та алюминий связывает все бо́льшую часть тантала и уменьшает его количество, которое вступает в реакцию с нижележащими слоями полупроводника, образуя соединение $\mathrm{TaN}$, ответственного за снижение приведенного контактного сопротивления. 

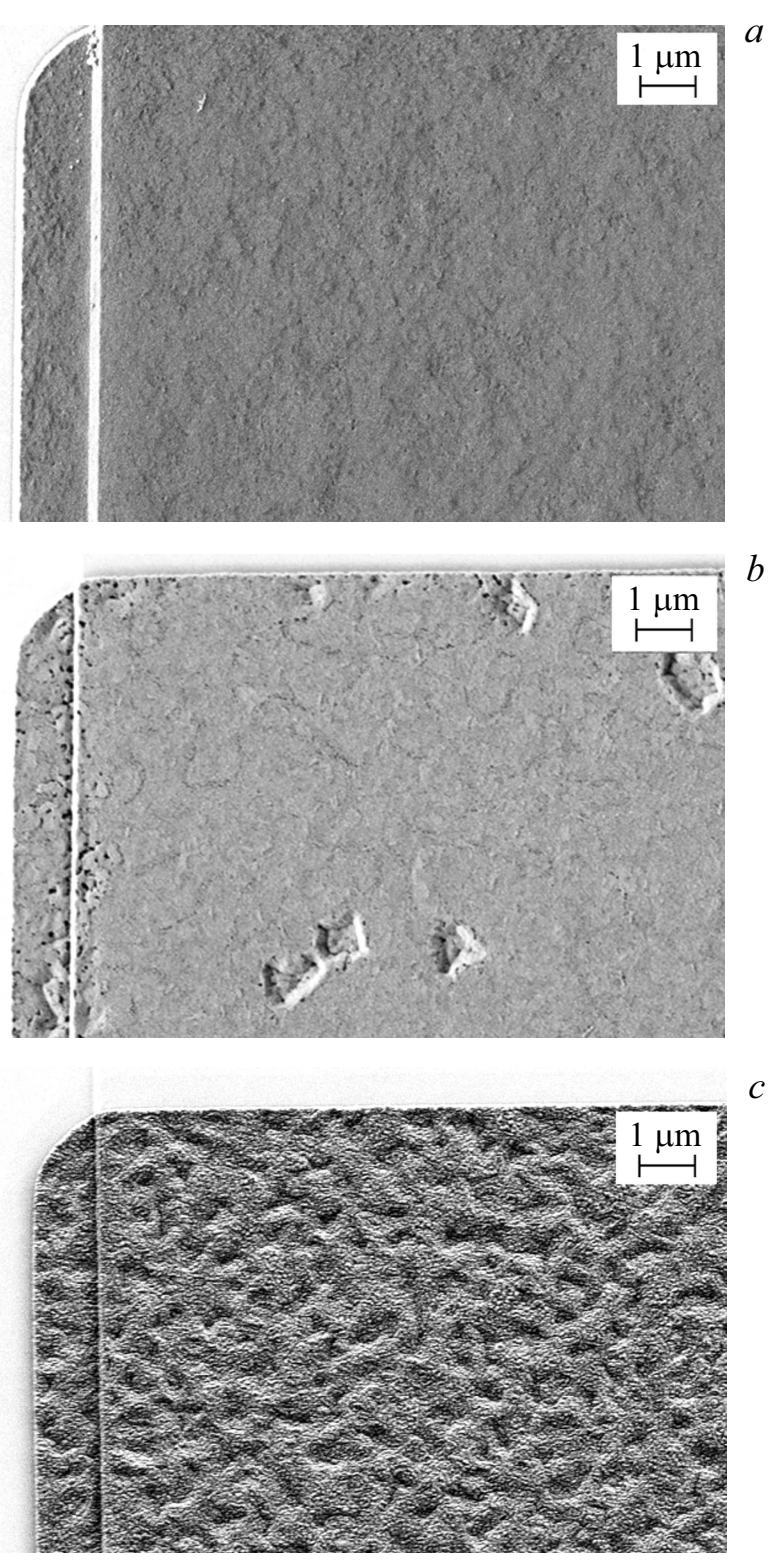

Рис. 3. Микроскопические изображения поверхности омических контактов на основе $\mathrm{Ta} / \mathrm{Al} / \mathrm{Ti}(a), \mathrm{Ta} / \mathrm{Al} / \mathrm{Mo}(b)$ и $\mathrm{Ta} / \mathrm{Al} / \mathrm{Ni}(c)$ после термической обработки при температуре $T=550^{\circ} \mathrm{C}$ в течение $t=60 \mathrm{c}$ в среде азота.

На рис. 2 представлена экспериментальная зависимость величины приведенного контактного сопротивления омического контакта на основе Тa/Al/Ti $(X / 300 / 20$ нм $)$ от толщины слоя тантала в диапазоне от $X=5$ до 20 нм после термической обработки при температуре $T=550^{\circ} \mathrm{C}$ в течение $t=60$ с в среде азота.

Как видно из результатов, представленных на рис. 2, зависимость контактного сопротивления омического контакта на основе $\mathrm{Ta} / \mathrm{Al} / \mathrm{Ti}$ от толщины слоя Та имеет характерный минимум при толщине 10 нм. Дальнейшее увеличение толщины слоя Та с 10 до $20 \mathrm{нм}$ приводит к росту контактного сопротивления с 0.8 до $2.4 \mathrm{Oм} \cdot$ мм.
На рис. 3 представлены микроскопические изображения поверхности омических контактов на основе $\mathrm{Ta} / \mathrm{Al} / \mathrm{Ti}(a), \mathrm{Ta} / \mathrm{Al} / \mathrm{Mo}(b)$ и Ta/Al/Ni $(c)$ после термической обработки при температуре $T=550^{\circ} \mathrm{C}$ в течение $t=60$ с. Толщины слоев $\mathrm{Ta}, \mathrm{Al}$ и $\mathrm{Ti}(\mathrm{Mo}, \mathrm{Ni})$ составляли 10,300 и 20 нм соответственно.

Из рис. 3, $а$ видно, что омический контакт на основе композиции $\mathrm{Ta} / \mathrm{Al} / \mathrm{Ti}$ после термической обработки при температуре $T=550^{\circ} \mathrm{C}$ в течение $t=60 \mathrm{c}$ в среде азота демонстрирует гладкую морфологию поверхности контактной площадки, а также ровный край. При этом использование пленок Мо (рис. 3,b) и $\mathrm{Ni}$ (рис. 3,c) в качестве защитного слоя для пленки алюминия приводит к появлению локальных „кратеров“, а также развитому рельефу поверхности контактной площадки.

Тем не менее, несмотря на гладкую морфологию поверхности омического контакта на основе Тa/Al/Ti (рис. $3, a$ ) достигнутое значение минимального контактного сопротивления после низкотемпературной $\left(550^{\circ} \mathrm{C}\right)$ обработки составило 0.8 Ом · мм, что значительно выше значений (0.3-0.5 Ом - мм), достигаемых традиционными высокотемпературными омическими контактами на основе $\mathrm{Ti} / \mathrm{Al} / \mathrm{Ni} / \mathrm{Au}[3-5]$. Таким образом, для дальнейшего уменьшения контактного сопротивления $\mathrm{Ta} / \mathrm{Al}$ омических контактов было использовано формирование рецесса (углубления) в барьерном слое на основе $\mathrm{AlGaN}$ перед напылением металлизации.

На рис. 4 представлена экспериментальная зависимость величины приведенного контактного сопротивления омического контакта на основе $\mathrm{Ta} / \mathrm{Al} / \mathrm{Ti}$ $(10 / 300 / 20$ нм) от глубины рецесса барьерного слоя $\mathrm{AlGaN}$ после термической обработки при температуре $T=550^{\circ} \mathrm{C}$ в течение $t=60$ с в среде азота.

Как видно из рис. 4, приведенное контактное сопротивление омического контакта уменьшается по мере приближения границы контакта к области двумерного

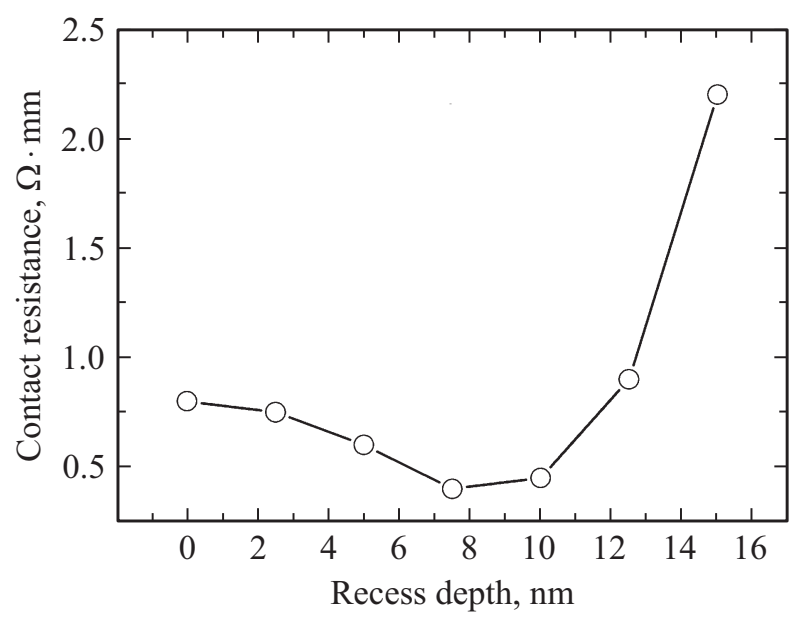

Рис. 4. Экспериментальная зависимость величины приведенного контактного сопротивления омического контакта на основе Ta/Al/Ti (10/300/20 нм) от глубины рецесса барьерного слоя $\mathrm{AlGaN}$ после термической обработки при температуре $T=550^{\circ} \mathrm{C}$ в течение $t=60 \mathrm{c}$ в среде азота. 
электронного газа, а затем резко возрастает при пересечении проводящего канала гетероструктуры $\mathrm{AlGaN} / \mathrm{GaN}$. Наблюдаемую зависимость можно объяснить следующим образом. При травлении слоя полупроводника уменьшается его количество, которое реагирует с нижележащими слоями металлов, благодаря чему взаимодействие металлов с полупроводником при температурном воздействии происходит более полно и в результате уменьшается сопротивление омического контакта. При залегании нижних слоев металлов ниже области двумерного электронного газа взаимодействия металлов с полупроводником не происходит, что приводит к росту контактного сопротивления.

Таким образом, при использовании травления рецесса на глубину 7.5 нм минимальное значение приведенного контактного сопротивления омического контакта Ta/Al/Ti (10/300/20 нм) составило 0.4 Ом · мм после термической обработки при температуре $T=550^{\circ} \mathrm{C}$ в течение $t=60 \mathrm{c}$ в среде азота. При этом изменений морфологии поверхности контактной площадки при использовании рецесса барьерного слоя выявлено не было, что свидетельствует о перспективности его использования для формирования низкоомных низкотемпературных омических контактов для мощных полупроводниковых приборов на основе гетероэпитаксиальных структур $\mathrm{AlGaN} / \mathrm{GaN}$ на кремниевых подложках.

\section{4. Заключение}

В работе изучены закономерности формирования низкотемпературного омического контакта на основе $\mathrm{Ta} / \mathrm{Al}$ к гетероэпитаксиальным структурам AlGaN/GaN на кремниевых подложках. Установлено, что минимальное значение приведенного контактного сопротивления $\mathrm{Ta} / \mathrm{Al}$ омического контакта достигается при толщинах пленок 10 и 300 нм соответственно. Выявлено влияние материала защитной пленки на основе $\mathrm{Ti}, \mathrm{Mo}, \mathrm{Ni}$ на морфологию поверхности контактной площадки. Показано, что использование рецесса в барьерном слое на основе $\mathrm{AlGaN}$ перед напылением металлизации омического контакта позволяет уменьшить значение приведенного контактного сопротивления.

В результате проделанной работы был получен омический контакт на основе $\mathrm{Ta} / \mathrm{Al} / \mathrm{Ti}$, характеризующийся низким значением приведенного контактного сопротивления $(0.4 \mathrm{OM} \cdot \mathrm{MM})$, а также гладкой морфологией поверхности контактной площадки и ее края после термической обработки при температуре $T=550^{\circ} \mathrm{C}$ в течение $t=60$ в среде азота.

Авторы работы выражают благодарность коллективу Научно-производственного комплекса „Микроэлектроника“ АО Научно-производственной фирмы „Микран“ и коллективу Научно-образовательного центра „Нанотехнологии“ Томского государственного университета Систем управления и радиоэлектроники за содействие в проведении экспериментальной части работы и обсуждении результатов.
Работа выполнена при финансовой поддержке Министерства образования и науки РФ (Соглашение № 14.577.21.0250 от 26.09.17). Уникальный идентификатор проекта RFMEFI57717X0250.

\section{Список литературы}

[1] M. Rosker, C. Bozada, H. Dietrich. CS MANTECH Conf. Proc. (Tampa, USA, 2009).

[2] В.Г. Мокеров, А.Л. Кузнецов, Ю.В. Федоров, Е.Н. Енюшкина, А.С. Бугаев, А.Ю. Павлов, Д.Л. Гнатюк, А.В. Зуев, Р.Р. Галиев, Е.Н. Овчаренко, Ю.Н. Свешников, А.Ф. Цацульников, В.М. Устинов. ФТП, 43 (4), 561 (2009).

[3] H.P. Xin, S. Poust, W. Sutton. CS MANTECH Conf. Proc. (Portland, Oregon, USA, 2010).

[4] V. Tilak, R. Dimitrov, M. Murphy, B. Green, J. Smart, W.J. Schaff, J.R. Shealy, L.F. Eastman. Mater. Res. Soc. Symp. Proc. 622, T7.4.1 (2000).

[5] F.A. Faria, J. Guo, P. Zhao, G. Li, P.K. Kandaswamy, M. Wistey, H.G. Xing, D. Jena. Appl. Phys. Lett., 101, 109 (2012).

[6] B. Van Daele, G. Van Tendeloo, W. Ruythooren. Appl. Phys. Lett., 87, 061905 (2005).

[7] M.W. Fay, G. Moldovan, P.D. Brown. J. Appl. Phys., 92, 94 (2002).

[8] F.M. Mohammed, L.K. Wang, S. Liang, H.H. Deepak, I. Adesida. J. Vac. Sci. Technol. B, 26 (3), 2330 (2005).

[9] A. Firrencieli, B. Jaeger, S. Decoutere. Jpn. J. Appl. Phys., 53, 03EF01-1 (2014).

Редактор А.Н. Смирнов

\section{Low temperature $\mathrm{Ta} / \mathrm{Al}$ based ohmic contacts to AIGaN/GaN heteroepitaxial structures on silicon wafers}

\author{
E.V. Erofeev ${ }^{1}$, I.V. Fedin ${ }^{1}$, V.V. Fedina ${ }^{1}$, A.P. Fazleev ${ }^{2}$ \\ ${ }^{1}$ Research Institute of Electrical Communication \\ Systems of Tomsk State University \\ of Control Systems and Radioelectronics, \\ 634050 Tomsk, Russia \\ ${ }^{2}$ Research Research \& Production Company Micran, \\ 634041 Tomsk, Russia
}

\begin{abstract}
The mechanisms of formation of low temperature $\mathrm{Ta} / \mathrm{Al}$ based ohmic contacts to $\mathrm{Al}_{0.25} \mathrm{Ga}_{0.75} \mathrm{~N} / \mathrm{GaN}$ heterostructures on silicon wafers were investigated. Fabricated ohmic contacts based on $\mathrm{Ta} / \mathrm{Al} / \mathrm{Ti}(10 / 300 / 20 \mathrm{~nm})$ have the low contact resistance $(0.4 \Omega \cdot \mathrm{mm})$ and smooth surface morphology and well defined contact edge after thermal annealing at $T=550^{\circ} \mathrm{C}$ during $t=60 \mathrm{~s}$ in nitrogen environment.
\end{abstract}

